\title{
Dynamic change of water level in flood season and sediment regulation in the Three Gorges Reservoir
}

\author{
Man Zhou ${ }^{1 *}$, Yangfan Xiao ${ }^{1}$, Chunming Fang ${ }^{2}$, Ting $\mathrm{Hu}^{1}$ \\ ${ }^{1}$ China Three Gorges Corporation, Hubei Yichang 443133 \\ 2. China Institute of Water Resources and Hydropower Research, Beijing 100044
}

\begin{abstract}
Based on the operation requirements of flood control, navigation, power generation, flood resource utilization and sediment reduction, this paper developed the schemes with dynamic change of water level at different periods in flood season, and focused on the response relationship between the different schemes with dynamic change of water level in flood season and the change of sediment erosion under the new water and sediment and the measured water and sediment conditions. The results indicate that the total sedimentation volume and the sedimentation volume above elevation $145 \mathrm{~m}$ are basically about twice that of the new water and sediment series, since the amount of sand entering the reservoir in 2003-2012 is basically twice that of the new flow water and sediment series. Regardless of the type of water and sediment series, the scheme with dynamic change of water level is better than the preliminary design expectation in terms of reservoir siltation and storage capacity loss.
\end{abstract}

\section{Introduction}

The Three Gorges Reservoir has huge comprehensive benefits, such as flood control, power generation, shipping, ploughing to the downstream, et al. The conditions of water and sediment storage in the Three Gorges Reservoir have undergone major changes since the 1990s, due to the construction of upstream reservoirs and climate change. Since the impoundment of the Three Gorges Reservoir, the annual average water volume has reached 400 billion $\mathrm{m}^{3}$, which is 51 billion $\mathrm{m}^{3}$ less than the average value of the preliminary design. The annual average amount of sand entering the reservoir is 155 million tons, which is only $30 \%$ of that in demonstration stage. In addition to major changes in water and sediment condition, the requirement of the reservoir operation of flood control, power generation, shipping, water supply and hydrometeorological forecasting level have also changed significantly from the preliminary design stage. In order to adapt to the new operating conditions, the Three Gorges Reservoir's operation mode has been optimized and adjusted, mainly in the aspect of water storage and operation in flood season. In order to alleviate the contradiction between reservoir storage and water supply for lower reaches, the Three Gorges Reservoir which has the storage capacity of 22.15 billion $\mathrm{m}^{3}$ regulated water flow from 10.5 to 12.87 billion $\mathrm{m}^{3}$ until the end of September. In order to reduce the pressure of the flood control and shipping in the middle and lower reaches of the Yangtze River and take flood resource utilization into account, the water level in the flood season has been dynamically controlled.
Compared with the preliminary design and operation method, there is a certain increase of the running water level of the Three Gorges Reservoir from June to September under the condition of the new water and sediment schemes and optimized operation modes. The response relationship between the new operation mode and sediment erosion and siltation is an important topic in the research of key technologies for reservoir operation ${ }^{[1,}$ ${ }^{2]}$. Based on the demand for the operation adjustment of the Three Gorges Reservoir under the new water and sediment situation, this paper proposed dynamic control schemes of water level in flood season under controllable flood risk. The conditions of new water and sediment series and the measured ones were established. And the response relationship between different water level schemes with dynamic change in flood season and sediment erosion and siltation was built. Finally, the water level schemes with dynamic change in flood season, which consider both controllable flood risk and erosion and deposition of sediment.

\section{The Operation Requirement of the Three Gorges Reservoir in Flood Season}

\subsection{Requirement of Flood Control}

In the preliminary design stage, the flood control objective of the Three Gorges Reservoir is mainly to improve the flood control standards in the Jingiiang area [3]. In general, flood control compensation operation is implemented for the Jingiiang area mainly for floods with an inflow of more than $55,000 \mathrm{~m}^{3} / \mathrm{s}$. Since 2009 , in order

*Corresponding author, e-mail: zhou_man@ctg.com.cn 
to reduce the flood control pressure in the vicinity of Chenglingji, the "Three Gorges Reservoir Optimized Operation Plan" approved by the State Council has clearly proposed the operation of the use of the reservoir capacity below $155 \mathrm{~m}$ to compensate the flood control for Chenglingji. In the flood season of year 2016 and 2017, the Three Gorges Reservoir implemented typical flood control operations for Chenglingji for the midstream and downstream flood of the Yangtze River (the maximum peak flow of the Three Gorges Reservoir was 50,000 and $38,000 \mathrm{~m}^{3} / \mathrm{s}$ respectively), which played a key role in avoiding flooding in Chenglingji area. Compared with the flood control compensation and operation mode for Jingjiang, the flood control compensation operation mode for Chenglingji mainly improves the effect of flood control and compensation of the Three Gorges Reservoir on general floods (the inflows below $55,000 \mathrm{~m}^{3} / \mathrm{s}$ ). In addition to these two types of flood control compensation modes, the society has higher and higher requirements for flood control with the development of the social economy in the middle and lower reaches of the Yangtze River. The local government along the Yangtze River hopes that the Three Gorges Reservoir can impound flood water as much as possible when conditions permit, so as to alleviate the flood control pressure of middle and lower reaches and provide a peaceful environment for economic and social development.

\subsection{Requirement of Power Generation}

The total installed capacity of the Three Gorges Power Station reached 22.5 million $\mathrm{kW}$, and the average annual power generation was 88.2 billion $\mathrm{kW} \cdot \mathrm{h}$. The huge installed capacity and power generation can effectively alleviate the power shortage in Central China, East China and Guangdong Province, and make a significant contribution to China's national economy and the development of the Yangtze River Economic Belt. In addition to direct power generation benefits, the Three Gorges Power Station can generate huge environmental benefits in place of thermal power, greatly saving primary energy consumption, reducing carbide and sulfide gas emission, and promoting the reform of China's energy structure. In terms of power generation, the power generation of the Three Gorges Power Station from June to October accounted for $60 \%$ of the annual power generation. It can be seen that the benefit of power generation in the flood season plays an important role in improving the benefit of power generation throughout the year. However, in order to meet the requirement of flood control, the Three Gorges Reservoir generally maintains a lower water level during flood season. How to make full use of the benefit of power generation under the premise of meeting flood control requirements is also a realistic demand for reservoir operation.

\subsection{Requirement of Navigation}

The Three Gorges Reservoir has fundamentally improved the navigation conditions of the Yangtze River through reasonable storage and drainage ${ }^{[4]}$. However, in the face of floods with high peak and large amount during the flood season, there will inevitably be a detention phenomenon of the crossing ship between the two dams, especially small and medium power ships. According to the relevant documents of the shipping department, the navigation between the Three Gorges and Gezhouba is graded and restricted when the discharge of the Three Gorges flow of $30,000 \sim 45,000 \mathrm{~m}^{3} / \mathrm{s}$. In view of the backlog of small and medium-sized vessels between two dams under large flow and the practical difficulties that may cause social instability, the shipping department hopes that the Three Gorges Reservoir will implement operation for ship evacuation by reducing the discharge flow and day-night differential operation without affecting the flood control safety, so as to alleviate the navigation pressure between the two dams.

\subsection{Requirement of Flood Resource Utilization}

Since 1877 in which Yichang station began recording data, the number of days with flood discharge above 55,000 $\mathrm{m}^{3} / \mathrm{s}$ is only 1.33 days per year, while the flood discharge in the interval of 30,000 to $55,000 \mathrm{~m}^{3} / \mathrm{s}$ occur on average more than 35 days per year. If the Three Gorges Reservoir only intercepts flood above $55,000 \mathrm{~m}^{3} / \mathrm{s}$, there will be a phenomenon of low utilization of flood control capacity and waste of flood resources. Therefore, it is necessary to improve the utilization of flood resources to achieve the transition from flood control to flood resource management.

\subsection{Requirement of Sediment Reduction}

Since the impoundment of the Three Gorges Reservoir, the annual average amount of sediment storage has reached 155 million tons, which is only $30 \%$ of that in the demonstration stage. The average annual siltation of sediment is 115 million tons, which is only $35 \%$ of that in the demonstration stage. Although the sedimentation of the reservoir is better than the preliminary design expectations, it is still necessary to further grasp the law of sediment erosion and sedimentation and study the reservoir operation mode for reducing the sedimentation in the reservoir and the scheduling method suitable for the normal development of the middle and lower reaches, in order to maintain the effective storage capacity of the reservoir for a longer period of time and avoid the obstacles caused by local sedimentation.

\section{Calculation Schemas and Conditions of Erosion and Deposition}

\subsection{Calculation Schemas of Erosion and Deposition}

Dynamic control of reservoir water level in flood season is one of the flood control operation manners of reservoir ${ }^{[5,6]}$. Based on the flood characteristics of the Three Gorges Reservoir during flood season, the characteristic water level and characteristic flow, $\mathrm{Hu}$ Ting ${ }^{[7]}$ divided the flood 
season into two periods from mid-June to late-August and early-September, and drafted the control water levels and operation rules for different time periods. The control water level is $145-158 \mathrm{~m}$ from mid-June to late August, and the control water level is $150-158 \mathrm{~m}$ in early September. The operation rules for different time periods are shown in Table 1.

Table 1 The operation rules ( $Q_{\text {in }}, Q_{\text {out }}, Q_{3 d}$, Q full and Qomin respectively represent inflow, outflow, 3-day average flow, the inflow meeting full power and the minimum outflow. $\mathrm{Z}$ and $\mathrm{Z}_{\mathrm{c}}$ respectively represent water level of reservoir and controlled water level)

\begin{tabular}{|c|c|}
\hline \multicolumn{2}{|c|}{ Operation rules } \\
\hline Mid-June to late-August & Early-September \\
\hline 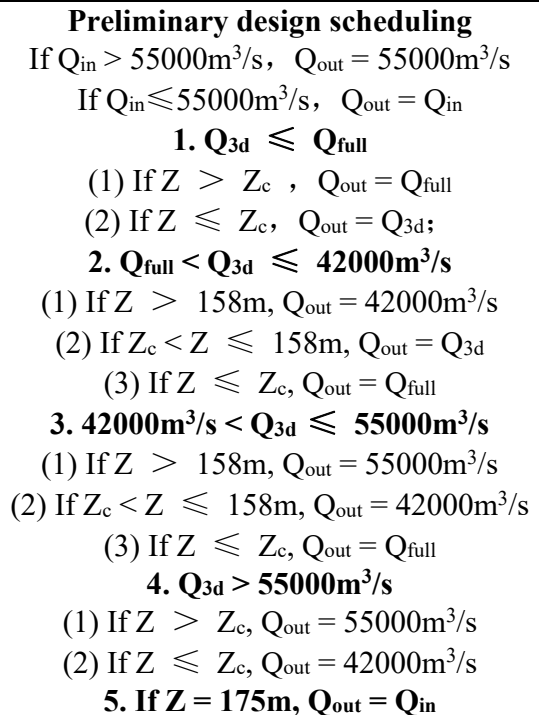 & $\begin{array}{l}\text { 1. Evenly raise the water level until the target. } \\
\text { 2. Qout } \leqslant 42000 \mathrm{~m}^{3} / \mathrm{s} \text { and } \mathrm{Q}_{\text {omin }} \geqslant 10000 \mathrm{~m}^{3} / \mathrm{s} \\
\text { 3、When } \mathrm{Q}=175 \mathrm{~m}, \mathrm{Q}_{\text {out }}=\mathrm{Q}_{\text {in }}\end{array}$ \\
\hline
\end{tabular}

The calculation results show that the operation rule can reduce the flood control pressure, increase the navigation time, effectively utilize the flood resources without reducing the flood control standards of the Three Gorges, and increase the average annual power generation during the flood season. Compared with the preliminary design method, the average annual power generation in the flood season is increased by more than $8 \%$, and the comprehensive utilization benefit of the Three Gorges Reservoir in flood season is fully utilized.

In order to obtain the response relationship between different water level schemes with dynamic change in flood season and sediment erosion and siltation, a calculation scheme for sediment erosion and siltation is proposed, as shown in Table 2.

Table 2 The calculation schemes of erosion and deposition of sediment

\begin{tabular}{|c|c|c|c|}
\hline Scheme & $\begin{array}{l}\text { Control water level } \\
\text { in mid-June to late- } \\
\text { August }(\mathrm{m})\end{array}$ & $\begin{array}{l}\text { Control water level in } \\
\text { early-September }(\mathrm{m})\end{array}$ & Operation rules \\
\hline $\begin{array}{c}\text { Scheme1 }(145,145) \\
(145,145145)\end{array}$ & 145 & 145 & \multirow{7}{*}{ As Table 1} \\
\hline Scheme $2 （ 145,150)$ & 145 & \multirow{4}{*}{150} & \\
\hline Scheme $3(146.5,150)$ & 146.5 & & \\
\hline Scheme $4 \quad(148,150)$ & 148 & & \\
\hline Scheme $5 \quad(150,158)$ & 150 & & \\
\hline Scheme $6(155,155)$ & 155 & 155 & \\
\hline Scheme $7 \quad(158,158)$ & 158 & 158 & \\
\hline
\end{tabular}

\subsection{Sediment Series}

The new water and sediment series and the measured sediment series were respectively used as sediment calculation conditions. The new water and sediment conditions considered the influence of upstream construction on the basis of the 90 series ${ }^{[8]}$, and the measured water and sediment series adopts the measured values from 2003 to 2012, as shown in Table 3. In the case 
of running for 10 years, the amount of sediment inflow of main stream is 106.9 million tons in the new water and sediment conditions, and the water volume is 360.5 billion $\mathrm{m}^{3}$. The water and sediment conditions of the Three Gorges in 2003-2012 are the annual average sediment storage capacity of the Zhuliu River is 168 million tons, and the average annual sand amount of the tributaries
Jialing River and Wujiang River are 29 million tons and 5.7 million tons respectively. The average annual storage of the sediment inflow of the three stations is 205 million tons, and the water volume is 360.5 billion $\mathrm{m}^{3}$. In addition, the annual average sediment inflow of small tributaries except the Jialing River and Wujiang River in the Three Gorges reservoir is considered at 10 million tons.

Table 3 Calculation conditions of sediment inflow

\begin{tabular}{|c|c|c|c|c|c|}
\hline & Zhu Tuo & Jialing River & Wujiang & \multicolumn{2}{|c|}{ In total } \\
\cline { 2 - 6 } Different series & $\begin{array}{c}\text { Sediment } \\
\text { discharge } \\
\text { (million } \mathrm{t})\end{array}$ & $\begin{array}{c}\text { Sediment } \\
\text { discharge } \\
\text { (million } \mathrm{t})\end{array}$ & $\begin{array}{c}\text { Sediment } \\
\text { discharge } \\
\text { (million } \mathrm{t})\end{array}$ & $\begin{array}{c}\text { Runoff } \\
\left.\text { (billion } \mathrm{m}^{3}\right)\end{array}$ & $\begin{array}{c}\text { Sediment } \\
\text { discharge } \\
\text { (million } \mathrm{t})\end{array}$ \\
\hline The new series & 82 & 19.1 & 5.8 & 375.9 & 106.9 \\
\hline The measured series & 169 & 29 & 5.7 & 360.5 & 205 \\
\hline
\end{tabular}

\section{Dynamic Change of Water Level in Flood Season and Erosion and Deposition}

The rise of water level in flood season will affect the sedimentation and erosion of the reservoir ${ }^{[9]}$. Taking the new water and sediment series and the measured water and sediment series from 2003 to 2012 as input, the effect of the dynamic change of water level in flood season on the erosion and sedimentation of the reservoir was analyzed.

\subsection{Reservoir Sedimentation}

When the different schemes of dynamic change of water level in flood seasons is used for 10 years, the results of the reservoir siltation with the measured water and sediment series and the new ones are shown in Table 4. It indicates that the annual average siltation of scheme 7 $(155,158)$ which is the most unfavorable with the new water and sediment series and 2003-2012 water and sediment series are respectively about 95 and 176 million tons. And scheme $5(150,158)$ were respectively 89 and 168 million tons. It is obvious that since the amount of sand inflow from 2003 to 2012 is basically twice that of the new water and sediment series, the amount of sedimentation in the reservoir is basically about twice that of the new water and sediment series.

The sedimentation amounts of the two water and sediment series are sequentially increased from scheme 1 to 7. Compared with scheme 1, the cumulative sedimentation of scheme 7 of the new water and sediment series increased by 179 million tons, with an average annual increase of about 17.9 million tons, which is increased by $10 \%$. While the cumulative sedimentation of 2003-2012 water and sediment series increased by 440 million tons, with an average annual increase of about 44 million tons which is increased by $33 \%$. The increase is about 1.5 times of the former. It means that under the conditions of water and sediment in 2003 2012, not only the sedimentation volume of the reservoir is large, but also the rate of siltation due to the dynamic change of the water level in the flood season is larger than that of the initial scheme, and the rate is about 1.5 to 2 times that of the new water and sediment series. Compared with the initial scheme, the annual average siltation of scheme 5 (150, 158 ) under the new water and sediment series and 20032012 water and sediment series are respectively increased by 12.4 and 36 million tons, with an increase of $16 \%$ and $27 \%$ respectively.

Table 4 Total sedimentation of different water and sediment series in different schemes (million $\mathrm{t}$ )

\begin{tabular}{|c|c|c|c|c|}
\hline \multirow{2}{*}{ Scheme } & \multicolumn{2}{|c|}{ New series } & \multicolumn{2}{c|}{ 2003-2012 series } \\
\cline { 2 - 5 } & $\begin{array}{c}\text { siltation } \\
\text { volume }\end{array}$ & $\begin{array}{c}\text { Comparison with } \\
\text { Scheme 1 }\end{array}$ & siltation volume & $\begin{array}{c}\text { Comparison with } \\
\text { Scheme 1 }\end{array}$ \\
\hline Scheme 1 (145,145) & 769 & 0 & 1320 & 0 \\
\hline Scheme 2 (145,150) & 842 & 73 & 1620 & 300 \\
\hline Scheme 3 (146.5,150) & 856 & 87 & 1640 & 320 \\
\hline
\end{tabular}




\begin{tabular}{|l|c|c|c|c|}
\hline Scheme 4 (148,150) & 874 & 105 & 1670 & 350 \\
\hline Scheme 5 $(150,158)$ & 893 & 124 & 1680 & 360 \\
\hline Scheme 6 (155,155) & 931 & 162 & 1730 & 410 \\
\hline Scheme 7 (158,158) & 948 & 179 & 1760 & 440 \\
\hline
\end{tabular}

\subsection{The Distribution of Sedimentation}

The statistic of the amount of sedimentation in the dynamic backwater area and the annual return water area in main stream under the new water and sediment series and 2003 to 2012 series is shown in Table 5. And figure 1 shows the distribution of sedimentation in main stream calculated with two kinds of water and sediment series using scheme 7. It is obvious that the distribution of cumulative sedimentation is similar, and the sedimentation mainly occurs from Fengdu to the reservoir area of dam site. There is slight erosion in the section from Fengdu to Chongqing under the new water and sediment conditions, while slight siltation under 2003 to 2012 water and sediment conditions.

Table 5 The amount of siltation in the main stream with different subsections (million $\mathrm{m}^{3}$ )

\begin{tabular}{|c|c|c|c|c|}
\hline \multirow{2}{*}{ Scheme } & \multicolumn{2}{|c|}{ New series } & \multicolumn{2}{c|}{ 2003-2012 series } \\
\cline { 2 - 5 } & $\begin{array}{c}\text { Zhu Tuo- } \\
\text { Qingxichang }\end{array}$ & Qingxichang-Dam & $\begin{array}{c}\text { Zhu Tuo- } \\
\text { Qingxichang }\end{array}$ & Qingxichang-Dam \\
\hline Scheme 1 (145,145) & -14.3 & 570 & -10 & 1280 \\
\hline Scheme 2 (145,150) & -14.1 & 623 & -9 & 1320 \\
\hline Scheme 3 (146.5,150) & -14.1 & 635 & -6 & 1330 \\
\hline Scheme 4 (148,150) & -14.1 & 647 & -1 & 1350 \\
\hline Scheme 5 (150,158) & -14 & 663 & 5 & 1370 \\
\hline Scheme 6 (155,155) & -12.8 & 701 & 32 & 1390 \\
\hline Scheme 7 (158,158) & -10.8 & 715 & 65 & 1370 \\
\hline
\end{tabular}

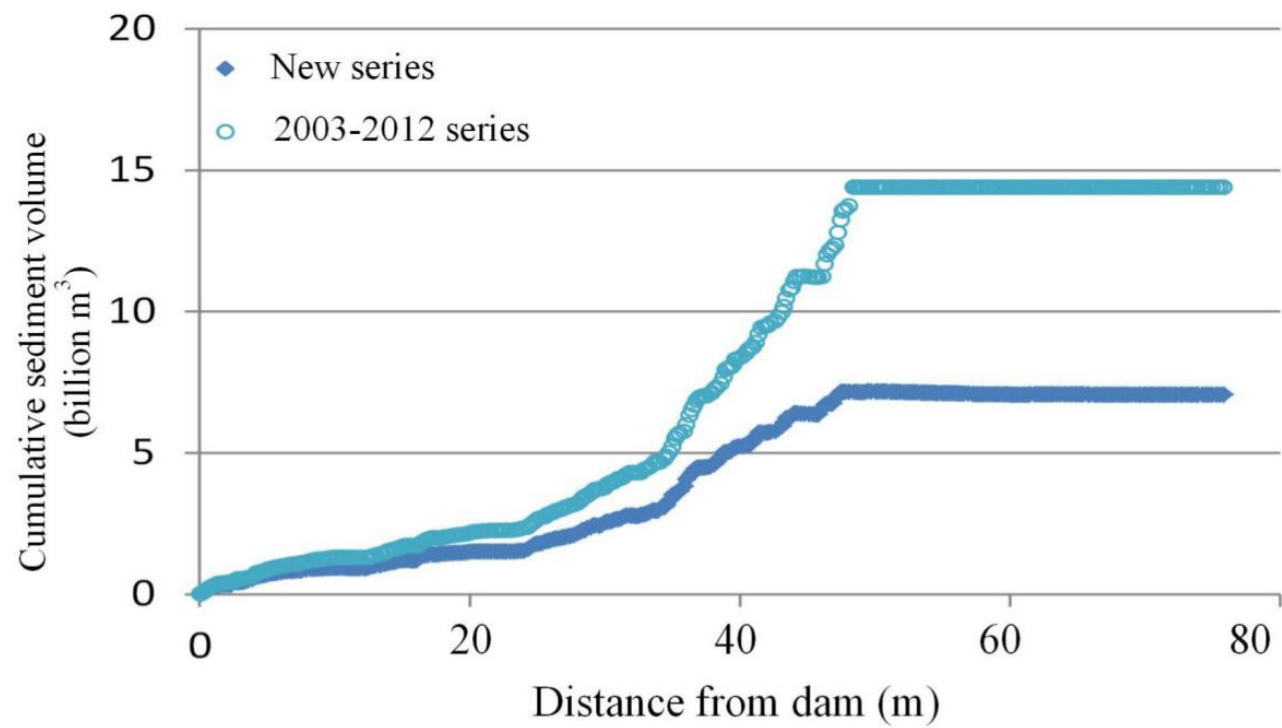

Fig. 1 The distribution of sedimentation in main stream calculated with two kinds of series (Scheme 7) 


\subsection{The Loss of Reservoir Storage Capacity}

In the case of running for 10 years, the loss of storage capacity within the interval $145-175 \mathrm{~m}$ and below $145 \mathrm{~m}$ in the main stream under different schemes is shown in Table 6. It is obvious that the sediment siltation of reservoir in the main stream area of each scheme is mainly located below the $145 \mathrm{~m}$ under the two kinds of water and sediment series, and the siltation in the range of elevation $145-175 \mathrm{~m}$ is small. However, the siltation in the range of $145-175 \mathrm{~m}$ has been significantly increased under the conditions of water and sediment in 2003 2012. And except for scheme 1, the other schemes are about twice as much as that of the new water and sediment series. In scheme $5(150,158)$, the cumulative loss of reservoirs for 10 years under the 2003-2012 water and sediment and new water and sediment series are respectively 105 and 55 million $\mathrm{m}^{3}$, and the former is 1.9 times the latter.

Table 6 The loss of reservoir storage capacity with different scheme in the case of sunning for 10 years $\left(\mathrm{million} \mathrm{m}^{3}\right)$

\begin{tabular}{|c|c|c|c|c|c|c|c|}
\hline Interval & $\begin{array}{l}\text { Scheme } 1 \\
(145,145)\end{array}$ & $\begin{array}{l}\text { Scheme } 2 \\
(145,150)\end{array}$ & $\begin{array}{l}\text { Scheme } 3 \\
(146.5,150)\end{array}$ & $\begin{array}{l}\text { Scheme } 4 \\
(148,150)\end{array}$ & $\begin{array}{l}\text { Scheme } 5 \\
(150,158)\end{array}$ & $\begin{array}{l}\text { Scheme } 6 \\
(155,155)\end{array}$ & $\begin{array}{l}\text { Scheme } 7 \\
(158,158)\end{array}$ \\
\hline & \multicolumn{7}{|c|}{ New series } \\
\hline $145 \mathrm{~m} \sim 175 \mathrm{~m}$ & -2 & 29 & 35 & 43 & 55 & 78 & 92 \\
\hline $145 \mathrm{~m}$ below & 613 & 639 & 645 & 650 & 654 & 671 & 673 \\
\hline In total & 611 & 668 & 680 & 693 & 709 & 749 & 765 \\
\hline Interval & \multicolumn{7}{|c|}{ 2003 2013 series } \\
\hline $145 \mathrm{~m} \sim 175 \mathrm{~m}$ & 53 & 61 & 72 & 87 & 105 & 158 & 196 \\
\hline $145 \mathrm{~m}$ below & 1257 & 1285 & 1296 & 1301 & 1308 & 1296 & 1278 \\
\hline In total & 1310 & 1346 & 1368 & 1388 & 1413 & 1454 & 1474 \\
\hline
\end{tabular}

From the view of the increase in siltation caused by different schemes of dynamic water level in flood season, under the new water and sediment series, the increase in siltation of the entire reservoir area is basically concentrated above the $145 \mathrm{~m}$. For example, compared with scheme 1, the total siltation amount in scheme 7 increased by 154 million $\mathrm{m}^{3}$, and the siltation amount above $145 \mathrm{~m}$ increased by 94 million $\mathrm{m}^{3}$, accounting for $61 \%$ of the total increase. And compared with scheme 1 , the total siltation amount in scheme 7 in the case of water and sediment in 2003-2012 increased by 164 million $\mathrm{m}^{3}$, and the siltation amount above $145 \mathrm{~m}$ increased by 143 million $\mathrm{m}^{3}$, accounting for $87 \%$ of the total increase. Compared with scheme 1, the total siltation in the reservoir area in scheme $5(150,158)$ under the conditions of new water and sediment and 2003 to 2012 water and sediment series respectively increased by 98 and 103 million $\mathrm{m}^{3}$, and the siltation above elevation $145 \mathrm{~m}$ respectively increased by 57 and 52 million $\mathrm{m}^{3}$, which respectively accounted for $58 \%$ and $50 \%$ of the total increase in the reservoir area. It can be concluded that although the effect of the rise of water level in flood season on the absolute loss of effective storage capacity is small, the relative value is still relatively large.

\section{Conclusion}

(1) Compared with the preliminary design, the flood control, navigation, power generation, flood resource utilization and sediment reduction and siltation have been put forward higher requirements for the operation of the Three Gorges Reservoir in flood season. In order to adapt to the new operating environment, the implementation of dynamic change of water level of Three Gorges Reservoir in flood season is necessary.

(2) Since the amount of sediment inflow in 2003 2012 is basically twice that of the new water and sediment series, the sedimentation volume of the reservoir is basically about twice that of the new water and sediment series. Compared with the preliminary design scheme, the sediment deposition increments of the two series with different schemes are 300-440 million tons and 73-179 million tons respectively.

(3) Under the conditions of new water and sediment and measured water and sediment, the cumulative sedimentation distribution of the Three Gorges Reservoir is similar, and the siltation mainly occurs from Fengdu to the reservoir area of dam site.

(4) Under the two kinds of water and sand series, the sediment siltation of reservoir in the main stream area 
using different schemes with dynamic water level is mainly located below $145 \mathrm{~m}$, and the siltation in the range of elevation $145-175 \mathrm{~m}$ is small. However, the siltation in the range of $145-175 \mathrm{~m}$ has been significantly increased under the condition of the measured water and sediment, and the siltation of all the schemes except for scheme 1 is about twice as much as that of the new water and sediment series.

\section{Acknowledgement}

The authors are grateful to the support of National Key Research and Development Program of China (No. 2016YFC0402306-01).

\section{Reference}

1. Minglei Ren, Xiaoyan He, et al. Review on the Methods of Fixing Dynamic Control Range of Reservoir Water Level in Flood Season. Water Power, 2016: p. 61-65.

2. Shijun Liu, Zhuang Li. Discussion on flood risk of dynamic control of limited water level of reservoir. Hydropower Engineering, 2017: p. 2901-2902.

3. Youcheng Yuan, Hong Zhang. Analysis of flood control situation in the middle and lower reaches of Yangtze River before and after the completion of the Three Gorges Project. Human Resources \& Social Science, 2015: p. 361.

4. Chuanzhou Xu. Navigation Function of the Three Gorges Project and Its Important Role in Chinese Economic Developmet. Hydropower and New Energy, 2016: p. 39-42.

5. Huicheng Zhou, Yongying Zhu, et al. Research on the Fuzzy Inference Dynamic Control Method for Flood Limited Level. Water Power, 2007, vol(33): p. 9-12.

6. Cheng Ding, Huicheng Zhou. Recent Progress and Development Trend of Dynamic Control of Flood Limited Water Level. China Flood \& Drought Management. 2018: vol(28) p. 103-107.

7. Ting $\mathrm{Hu}$, Man Zhou, et al. Study on hierarchical rules of Three Gorges reservoir for regulating small and medium floods. Journal of Hydroelectric Engineering. 2015: vol(34). p. 1-7.

8. Yongjun Lu, Liqin Zuo, et al. Changes of sediment deposition and erosion at Chongqing reach in backwater area of Three Gorges Project after reservoir adjusting of the upstream in the Yangtze River. Advances in Water Science. 2009: vol(20). p. 318-324.

9. Jian Chen, Yitian Li, et al. Influence on deposition in Three Gorges reservoir caused by regulation optimization of flood-controlled water level. Journal of Hydroelectric Engineering, 2012. vol(31): p. 183188. 